\title{
Factors Affecting the Stability and Physical Properties of Pickering Emulsions Stabilized by $\mathrm{Fe}_{3} \mathrm{O}_{4} @ \mathrm{CNC}$ Nanocomposites
}

\author{
Liang Ee Low ${ }^{1,2}$, Boon Hoong Ong ${ }^{3}$, Beng Ti Tey ${ }^{4,5}$, Siah Ying Tang ${ }^{4,5, *}$ \\ ${ }^{1}$ Institute of Pharmaceutics, College of Pharmaceutical Sciences, Zhejiang University, 866 Yuhangtang Road, Hangzhou \\ 310058, P. R. China. \\ ${ }^{2}$ Key Laboratory of Biomedical Engineering of the Ministry of Education, College of Biomedical Engineering \& Instrument \\ Science, Zhejiang University, Hangzhou 310058, P. R. China. \\ ${ }^{3}$ Nanotechnology \& Catalysis Research Centre, University of Malaya, Jalan Universiti, 50603 Kuala Lumpur, Wilayah \\ Persekutuan Kuala Lumpur, Malaysia. \\ ${ }^{4}$ Chemical Engineering Discipline, School of Engineering, Monash University Malaysia, Jalan Lagoon Selatan, Bandar \\ Sunway, 47500 Subang Jaya, Selangor, Malaysia. \\ ${ }^{5}$ Advanced Engineering Platform, Monash University Malaysia, Jalan Lagoon Selatan, Bandar Sunway, 47500 Subang Jaya, \\ Selangor, Malaysia.
}

\begin{abstract}
Particle-stabilized emulsion systems, namely Pickering emulsions have recently emerged as novel yet attractive dosage form for controlled delivery of biologically active compounds. The stability and properties of emulsions are influenced by formulation and processing factors. In this study, oil-in-water Pickering emulsions were prepared using Fe $\mathrm{O}_{4} @$ cellulose nanocrystal (MCNC) nanocomposites and the effects of $\mathrm{CNC} / \mathrm{Fe}_{3} \mathrm{O}_{4}(\mathrm{CNC} / \mathrm{MNP})$ ratios, $\mathrm{MCNC}$ particle concentration $\mathrm{C}_{\mathrm{menc}}$, oil volume fraction $\varphi_{\text {oil }}$ and ionic strength on the colloidal stability were evaluated. The results showed that stable emulsions could be attained using MCNC particles with $\mathrm{CNC} / \mathrm{MNP}$ ratio $\leq 1$. Increasing $\mathrm{CNC} / \mathrm{MNP}$ ratio $>1$ resulted in different degree of phase separation of emulsions. The average droplet size of MCNC-stabilized Pickering emulsions (MCNC-PE) decreased from 17.34 to $3.58 \mu \mathrm{m}$ with an increase in $\mathrm{C}_{\mathrm{mcnc}}$ as a result of improved coalescence stability due to higher droplet surface coverage $\mathrm{S}_{\mathrm{m}} \mathrm{nc}$ by MCNC particles. An increase in $\varphi_{\text {oil }}$ led to pronounced increase in droplet size from 2.82 to $17.00 \mu \mathrm{m}$. Interestingly, the ionic strength showed little or no impact on the emulsion droplet size and creaming. The storage stability study revealed that most emulsions remained fairly stable with no apparent change in droplet size. In conclusion, the physical stability of MCNC-PE was found to be greatly influenced by particulate emulsifier concentration and oil loadings. These two parameters must be well controlled in the development of Pickering emulsions for potential food and pharmaceutical applications.
\end{abstract}

Keywords: Pickering emulsions; $\mathrm{CNC} / \mathrm{Fe}_{3} \mathrm{O}_{4}$ ratio; particle concentration; oil loading; surface coverage; ionic strength.

Received: $10^{\text {th }}$ March 2020

Accepted: $12^{\text {th }}$ April 2020

Published Online: $21^{\text {th }}$ April 2020
*Correspondence: Siah Ying Tang, School of Engineering, Monash University Malaysia, Jalan Lagoon Selatan, Bandar Sunway, Subang Jaya, Selangor, Malaysia; patrick.tang@ monash.edu

Citation: Low, L. E., Ong, B. H., Tey B. T., \& Tang, S.Y. Factors affecting the stability and physical properties of pickering emulsions stabilized by $\mathrm{Fe}_{3} \mathrm{O}_{4} @$ cnc nanocomposites. Prog Drug Discov Biomed Sci 2020; 3(1): a0000073. https://doi. org/10.3687/pddbs.a0000073

\section{Highlights:}

Stability of Pickering emulsions can be influenced by MCNC loading with different CNC/MNP ratios.

Formation of stable emulsions was achieved using MCNC particles with $\mathrm{CNC} / \mathrm{MNP}$ ratio $\leq 1$

Increasing MCNC loading resulted in smaller droplets with comparable emulsion stability.

The oil volume fraction has significant impact on the emulsion droplet sizes.
Changes in ionic strength exhibited negligible impact on emulsion stability.

\section{Introduction}

An emulsion is a system consisting two immiscible liquids where one of the liquids is dispersed in the other. Emulsion system without a stabilizer is thermodynamically unstable and tends to experience serious inter-droplet coalescence and creaming ${ }^{[1-3]}$. Thus, the stabilizer has been an important ingredient 
for the preparation of stable emulsions that resist coalescence. Conventionally, emulsions are stabilized by chemical surfactants. However, excessive usage of surfactants often results in drawbacks including cost, toxicity, and tissue irritation ${ }^{[4]}$. To address such issues, particle-stabilized emulsions or Pickering emulsions with surfactant-free nature has been proposed $^{[5-8]}$. Pickering stabilization occurs through the irreversible attachment of partial wettable particles onto the interface between the two immiscible liquids, which reduces the interfacial energy, a dominant driving force for the emulsion deformation ${ }^{[9-10]}$. Since its introduction by Ramsden $^{[11]}$ and Pickering ${ }^{[12]}$, Pickering emulsions have been receiving substantial attention by academic and industrial researchers owing to their lower cost, lowtoxicity and astonishing stability against coalescence compared to those stabilized by surfactants ${ }^{[1-14]}$. To date, Pickering emulsion can be considered as one of the researchers-preferred topics that have been extensively studied in the food ${ }^{[15-17]}$, biomedical ${ }^{[4,18-19]}$ and pharmaceutical sectors ${ }^{[13,20-21]}$.

With the increasing awareness in sustainability, "green" bio-based or hybrid nano-/micro-particles have received growing interest for Pickering emulsion preparation. Amongst, cellulose nanocrystal (CNC) that is biocompatible, biodegradable, non-toxic and sustainable can be recognized as a promising candidate for Pickering stabilization ${ }^{[22-24]}$. CNCs were previously confirmed to yield highly stable Pickering emulsion ${ }^{[23-26]}$. Additionally, the reactive functional group-rich nature of $\mathrm{CNC}$ further inspired researchers to incorporate stimuli-responsive ligands to $\mathrm{CNC}$ to extend its usage in biomedical fields ${ }^{[4,27-28]}$. In past decades, various stimuli-responsiveness, namely thermal-, fluorescent-, $\mathrm{pH}-$ and magnetic- responsive materials have been reported for preparing CNC-based stimuli-controllable smart nanomaterials ${ }^{[27-30]}$. In fact, our research group has also prepared the Pickering emulsion stabilized by $\mathrm{Fe}_{3} \mathrm{O}_{4} @ \mathrm{CNC}$ (MCNC) nanocomposites previously, and demonstrated its potential as drug delivery carrier for colon cancer therapy ${ }^{[29-31]}$.

Despite the intensive efforts made on MCNC-stabilized Pickering emulsion (MCNC-PE), the influence of the compositional parameters and ionic strength on the properties and stability of MCNC-PE have not been systematically investigated. Herein, the current work aimed to study the impacts of $\mathrm{CNC} / \mathrm{Fe}_{3} \mathrm{O}_{4}(\mathrm{CNCN} /$ MNP) ratio, MCNC particle concentration $\mathrm{C}_{\mathrm{mcnc}}$ and oil volume fraction, $\varphi_{\text {oil }}$ on the characteristics and physical stability of MCNC-PE. As part of this study, the effect of physiological variable i.e. ionic strength on the physical and creaming stability of the Pickering emulsion were also evaluated. The findings of this parametric study provided further knowledge and understanding into the key factors affecting the colloidal stability and properties of magnetic Pickering emulsions stabilized by MCNC particles, which could be beneficial for the future formulation development of colloidal drug delivery platform for controlled delivery of therapeutic compounds.

\section{Materials and Methods}

\section{Materials}

Iron (II) chloride tetrahydrate $\left(\mathrm{FeCl}_{2} .4 \mathrm{H}_{2} \mathrm{O}, \geq 99 \%\right)$, iron (III) chloride hexahydrate $\left(\mathrm{FeCl}_{3} .6 \mathrm{H}_{2} \mathrm{O}, 99 \%\right)$, ammonium hydroxide $\left(28 \% \mathrm{NH}_{3}\right.$ in $\left.\mathrm{H}_{2} \mathrm{O}\right)$, calcofluor white (for microbiology) and potassium hydroxide were procured from Sigma-Aldrich Chemicals Company (Malaysia). CNC (freeze dried, $0.96 \mathrm{wt} \%$ sulphur content) was obtained from the University of Maine. Red palm superolein (275 ppm $\beta$-carotene, melting point $19^{\circ} \mathrm{C}$,) was purchased from Sime Darby Jomalina Sdn Bhd (Malaysia). All water used in this experiment is ultrapure and obtained from Milli-Q ${ }^{\circledR}$ Plus apparatus (Millipore, Billerica, USA). Ethanol (AR standard), Hydrochloric acid $(\mathrm{HCl}, 1 \mathrm{M})$, and sodium hydroxide $(\mathrm{NaOH})$ were received from R \& M Chemical (Syarikat Saintifik Jaya, Malaysia). All chemicals used in this study are of analytical grade.

\section{Synthesis of MCNC nanocomposites}

MCNC composites were prepared using the ultrasoundassisted in situ co-precipitation method ${ }^{[32]}$. First, CNCs with varying concentration $(0.01,0.05,0.1,0.5$ and 1 $\mathrm{wt} \%$ ) were dispersed in $80 \mathrm{ml}$ of water under sonication for 2 minutes. Subsequently, $0.054 \mathrm{~g}$ of iron (III) and $0.027 \mathrm{~g}$ iron (II) chloride $\left(1.5 / 1 \mathrm{Fe}^{3+} / \mathrm{Fe}^{2+}\right.$ mol ratio) were added to the $\mathrm{CNC}$ dispersion to obtain a $\mathrm{CNC} /$ MNP ratio of $0.2,1,2,10$ and 20, respectively. The mixtures were then stirred and heated to $45^{\circ} \mathrm{C}$. Next, the mixtures were treated with ultrasound $(60 \mathrm{w}, 5 \mathrm{~min})$ in the presence of ammonium hydroxide $(2.2 \mathrm{ml})$ to yield the MCNC nanocomposites. The resultant MCNCs were then precipitated, magnetically separated and washed 3 times with ethanol to remove all residual ammonium hydroxide. The recovered MCNCs were centrifuged at $4500 \mathrm{rpm}$ for 8 minutes, followed by drying in an oven for 24 hours, prior to its storage characterization. The prepared MCNC samples with different $\mathrm{CNC} / \mathrm{MNP}$ ratio are denoted as MCNC02, MCNC1, MCNC2, MCNC10 and MCNC20.

\section{Characterization of MCNC nanocomposites}

The size and surface morphology of the MCNC composites were analyzed by Hitachi SU8010 field emission scanning electron microscope (FE-SEM) (Hitachi, Japan) via scanning transmission electron microscopy (STEM) mode at $15 \mathrm{kV}$. Available functional groups were examined using a Fourier transform infrared (FTIR) spectrophotometer equipped with a diamond probe (Nicolet iS10, Thermo Scientific, USA) in a frequency range of $550-4000 \mathrm{~cm}^{-1}$. The magnetization of MCNC was measured via vibrating sample magnetometry (VSM) (Lakeshore 7400 Series). The thermal stability was examined using a thermogravimetric analyzer (Q50 TGA, TA instrument, USA) over a temperature range of 25 to $900^{\circ} \mathrm{C}$ at $10^{\circ} \mathrm{C} / \mathrm{min}$.

\section{Preparation of MCNC-PE}

The MCNC-PE was prepared using the as-synthesized MCNC nanocomposites as the stabilizers and $\beta$-carotene 
rich palm olein as the oil phase. All emulsion samples were transferred to glass vials and stored at room temperature for further characterization. The preparation procedure of MCNC-PE with different formulations is as follow.

\section{$M C N C-P E$ with different $C N C / M N P$ ratio}

Emulsions with a fixed $\varphi_{\text {oil }}(0.3)$ and a fixed $\mathrm{C}_{\text {menc }}(0.1$ wt $\%$ ) were prepared by using MCNC with different $\mathrm{CNC}$ to MNP ratio $(0.2,1,2,10,20)$. The mixture was emulsified for 3 minutes using an ultrasound probe sonicator $(20 \mathrm{kHz}$, Lab750, NexTgen ultrasonic platform, Sinaptec, France) under pulse mode ( $15 \mathrm{~s}$ pulse on, $10 \mathrm{~s}$ pulse off).

\section{MCNC-PE with various MCNC particle concentrations}

Emulsions were produced using the MCNC1 sample under a fixed oil content $\left(\varphi_{\text {oil }}=0.3\right)$ with varying aqueous suspension of different $C_{\text {mcnc }}(0.025,0.050,0.100,0.200$, and $0.300 \mathrm{wt} \%$ ). The mixture was then emulsified for 3 minutes using pulse mode sonication.

\section{$M C N C-P E$ with different oil volume fraction}

Emulsions with various $\varphi_{\text {oil }}$ were prepared by combining $\mathrm{C}_{\mathrm{mcnc}} 0.1 \mathrm{wt} \%$ (MCNC1 sample) and different oil volume fractions $\left(\varphi_{\text {oil }}=0.1,0.2,0.3,0.4\right.$, and 0.5$)$. The mixture was emulsified for 3 minutes under pulse-mode sonication.

\section{Effects of NaCl on MCNC-PE stability}

The effect of salt on the properties of MCNC-PE was evaluated by adding various quantities of $\mathrm{NaCl}(0,100$, $200,300,400,500 \mathrm{mM}$ ) into the freshly made Pickering emulsions with the following formulation $\left(\varphi_{\text {oil }}=0.3\right.$, $\mathrm{C}_{\mathrm{mcnc}}=0.1 \mathrm{wt} \%, \mathrm{MCNC1}$ sample). The MCNC-PEs were stirred at $200 \mathrm{rpm}$ for $5 \mathrm{~min}$ before storage.

\section{Characterization of MCNC-PE}

The hydrodynamic diameter of the MCNC-PE was measured via laser diffraction using a Mastersizer (Mastersizer 3000, Malvern Instruments, UK) equipped with a Hydro EV wet dispersion unit. The images of MCNC-PE were obtained using an inverted fluorescent/optical microscope (Nikon Eclipse TS100, Nikon Instruments Inc., USA) at 10x magnification. The adsorption of MCNC particle at the oil/ water interface was determined by chemically staining a representative emulsion sample (MCNC-PE stabilized by $0.05 \mathrm{wt} \% \mathrm{MCNC}$ particles) with calcofluor white prior to the fluorescence microscopy. The staining procedure was carried out as described in our previous work ${ }^{[29]}$.

\section{Storage stability of MCNC-PE}

The MCNC-PEs were stored at room temperature $\left(25^{\circ} \mathrm{C}\right)$ for 14 days. The stability of emulsions against coalescence and creaming was monitored after 0,7 , and 14 days of storage in term of droplet diameter and creaming profile via the standard laser diffraction and emulsion storage properties analysis ${ }^{[33]}$.

\section{Statistical analysis}

Analysis of variance (ANOVA) were conducted using Prism software and $p<0.05$ was considered as statistically significant.

\section{Results and discussion}

\section{Characterization of MCNC nanocomposites}

MCNC nanocomposites were synthesized using the previously developed method ${ }^{[32]}$. The STEM micrograph of MCNC1 sample revealed the uniform deposition of MNPs onto the rod-like CNCs (Figure 1a). The MCNC1 sample was observed to exhibited superparamagnetic properties with a saturation magnetization $\left(M_{\mathrm{s}}\right)$ of 28.31 $\mathrm{emu} / \mathrm{g}$ (Figure 1b), comparable to those previously reported ${ }^{[34]}$. However, the FTIR curves showed that the characteristics $\mathrm{C}-\mathrm{OH}$ bonding of $\mathrm{CNCs}$ were prominent in $\mathrm{MCNC} 10$ and $\mathrm{MCNC} 20$ samples (Figure 1c), suggesting the presence of abundant surface hydroxyl groups of CNCs as compared to the insufficient iron precursors for a complete reaction. The ash content of MCNC was found to decrease with increasing $\mathrm{CNC}$ concentration, which was primarily attributed to the decreased MNP content in MCNC nanocomposites as CNC/MNP ratio increased. Interestingly, the typical weight loss induced by the removal of MNP-bonded oxygen atoms (at approximately $780^{\circ} \mathrm{C}$ ) only existed when the CNC/MNP ratio is $\leq 1$ (Figure 1d) ${ }^{[34]}$. This demonstrated the decrease in the thermal stability of MNPs upon reaction with the hydroxyl groups of CNC. This is most likely owing to the crystalline structure of MNP in each MCNC sample, as reported by KalskaSzostko et al. where supreme thermal stability was observed on monocrystalline MNP as compared to the less dense polycrystalline MNP ${ }^{[35]}$. Hence, the reduction in thermal stability in MCNC01, MCNC1, and MCNC2 simply indicated that a less dense crystalline structured MNP is presence in the mentioned samples while a monocrystalline structured MNPs are found in MCNC10 and MCNC20. Apart from that, the TGA curves of both MCNC02, and MCNC2 also revealed a lower second weight loss than the MCNC1. This phenomenon may be due to the presence of monocrystalline structured MNPs with a higher thermal stability ${ }^{[35]}$. Using the weight loss curve, the MNP content in the as-prepared MCNC nanocomposite are determined at approximately 80,55 , 45,30 and $20 \mathrm{wt} \%$ for $\mathrm{MCNC} 02, \mathrm{MCNC} 1, \mathrm{MCNC} 2$, $\mathrm{MCNC} 10$ and MCNC20 respectively. 


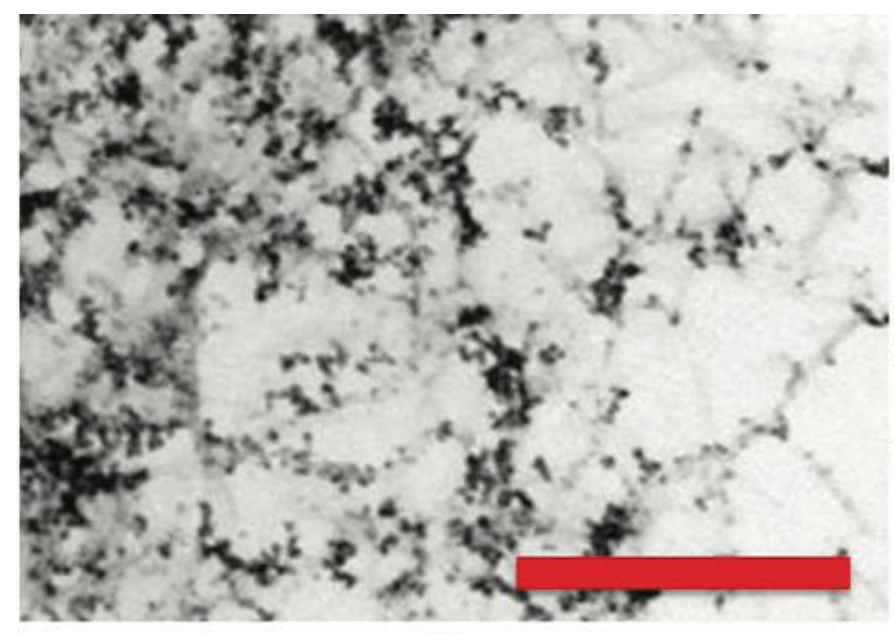

(a)

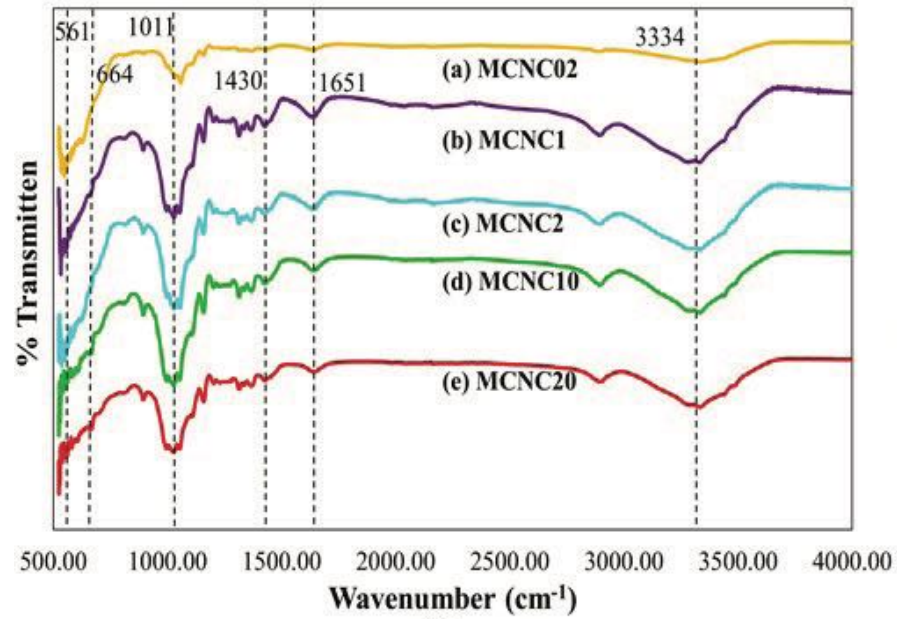

(c)

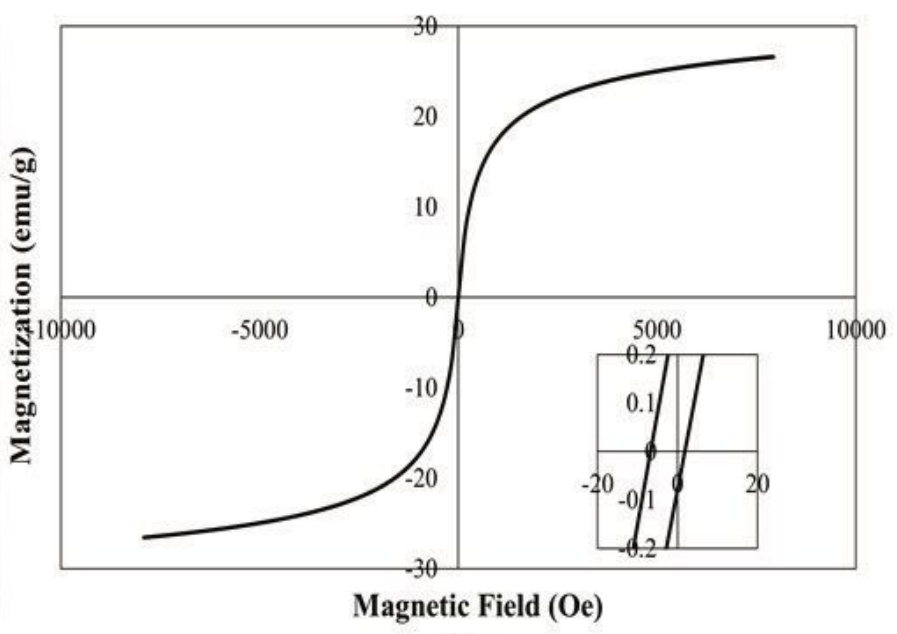

(b)

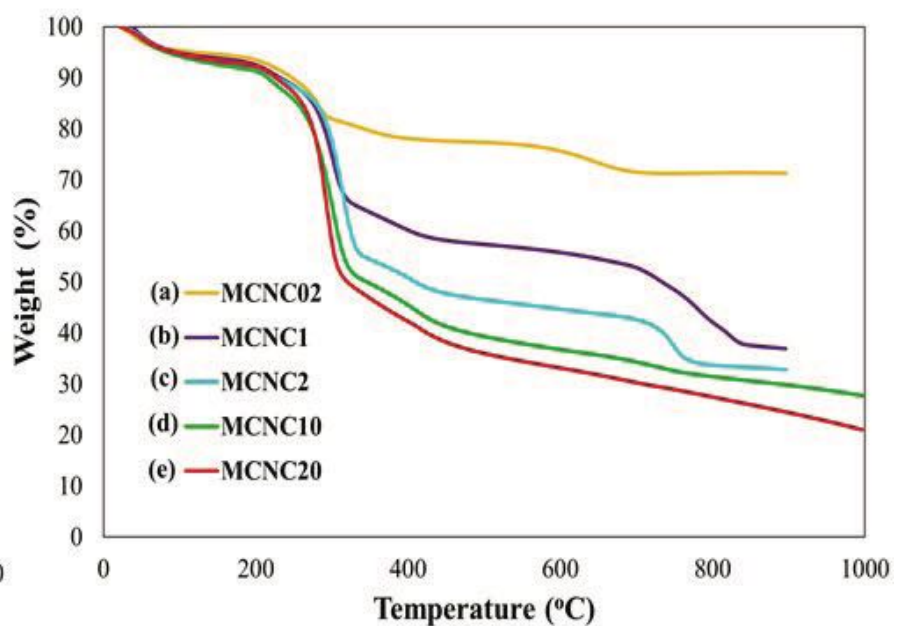

(d)

Figure 1. (a) FESEM image and (b) VSM data for MCNC1 sample. (c) FTIR spectra and (d) TGA data of MCNC nanocomposite with CNC/MNP ratio of (i) 0.2 , (ii) 1 , (iii) 2 , (iv) 10 and (v) 20 . Scale bar represents $200 \mathrm{~nm}$.

\section{Properties of MCNC-PE}

\section{Varying CNC/MNP ratio}

MCNC nanocomposites with different CNC/MNP ratio were used to prepare the MCNC-PE. The laser diffraction results show the emulsions with monomodalsized distribution when the CNC/MNP ratio was $\leq 1$. Contrarily, bimodal distribution with multiple peaks was noticed at emulsion samples prepared using MCNC2, MCNC10 and MCNC20 (Figure 2a). Similar observation was noticed in the optical microscopy analysis (Figure 2c). Evidently, the optical images of Pickering emulsion stabilized by MCNC2, MCNC10 revealed emulsion droplets with a large size ranges, demonstrating the possible coalescence of MCNC-PE prepared using MCNC with CNC/MNP ratio of $\geq 2$. This shows that the successful stabilization of MCNC-PE is only possible at $\mathrm{CNC} / \mathrm{MNP}$ ratio is $\leq 1$, and the finest emulsion droplet $(\approx 7 \mu \mathrm{m})$ was obtained using $\mathrm{MCNC1}$ as stabilizer (Figure 2b). This indicated that the MCNC1 is likely to be the most desired CNC/MNP ratio for the preparation of stable MCNC-PE. To verify the claim further, the emulsion samples were subjected to storage stability analysis to monitor the changes in size and creaming index. It was noticeable that only the size of emulsions fabricated using MCNC1 remained the same throughout the storage period at room temperature (Figure $2 \mathrm{~b}$ ). In term of creaming profile, the extent of droplet creaming was measured by the change in height of the bottom serum phase with storage time. The creaming index (CI) was determined according to Equation 1.

$C I=\left(h_{\text {total }}-h_{\text {emul }}\right) / h_{\text {total }} \times 100 \%$

where CI represents the creaming index, is the height of emulsion, and is the total height of all solutions.

Based on Figures $3 \mathrm{~b}$ and $\mathrm{c}$, lowest CI was recorded at $\mathrm{CNC} / \mathrm{MNP}$ ratio $=1$ (Figure $3 \mathrm{c}$ ). Since creaming is known to occurs as a result of the density difference between the dispersed (oil) and the continuous (water) phases, and larger oil globule usually experienced a greater influences 


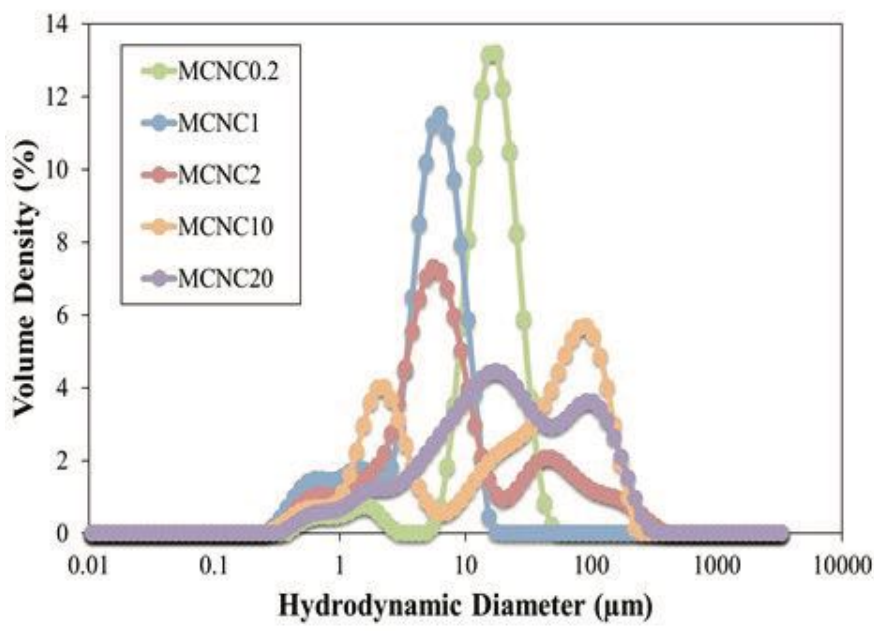

(a)

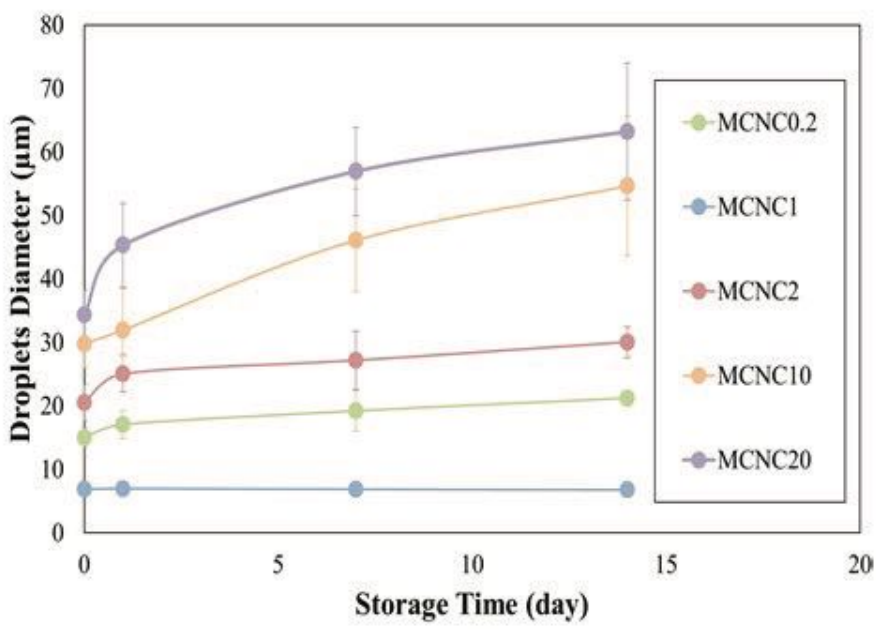

(b)

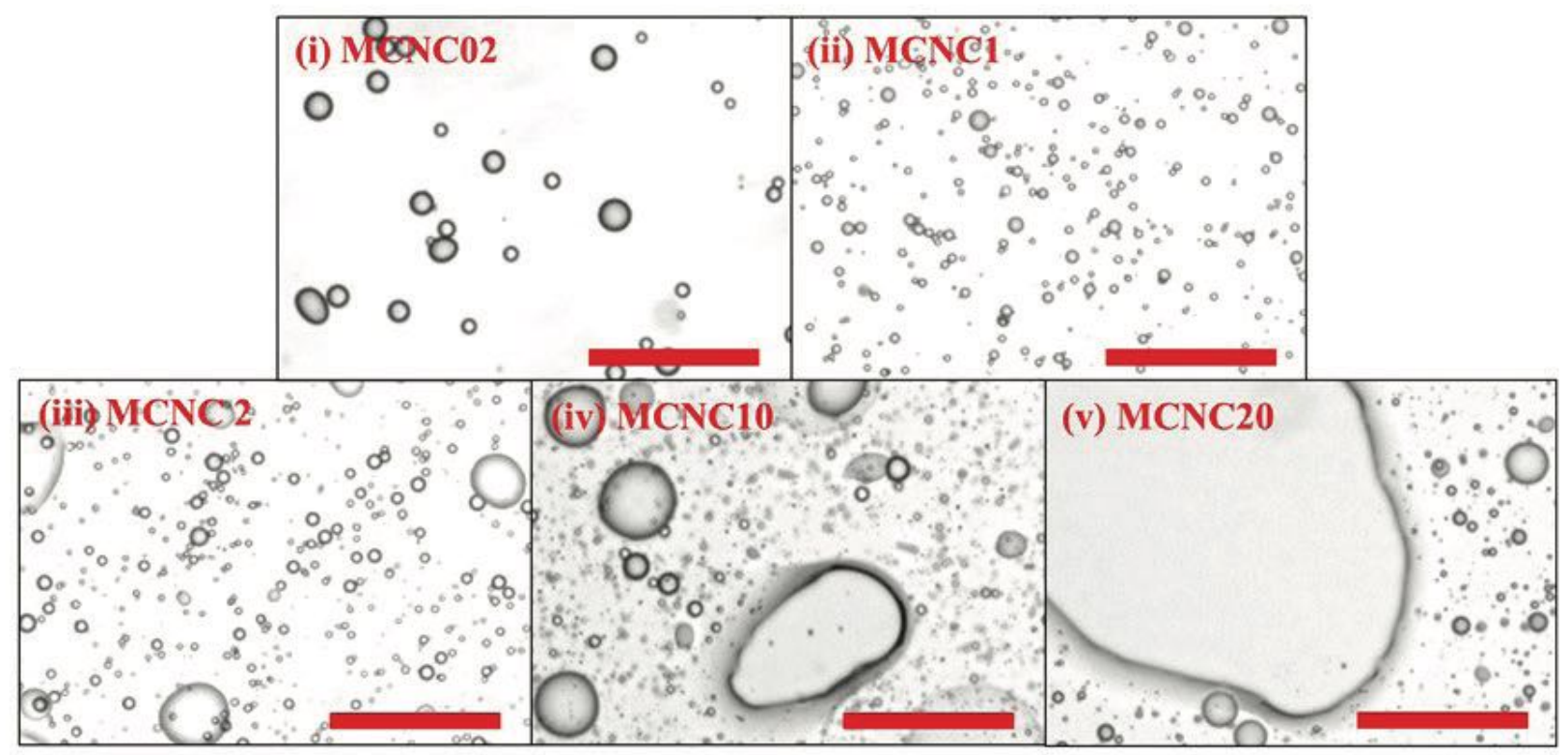

(c)

Figure 2. (a) Droplet size distributions, (b) emulsion diameter changes over 14 days and (c) microscopic images of MCNC-PE as a function of CNC/MNP ratio. All formulations contain a fixed $\mathrm{C}_{\mathrm{mcnc}}$ of $0.1 \mathrm{wt} \%$ and $\varphi_{\mathrm{oil}}$ of 0.3 . The standard error of the mean of triplicate readings was represented by the error bars in each graph, and different alphabetic letters were significantly different at $\mathrm{P} \leq 0.05$ using Bonferroni's multiple comparison test. All scale bars represent $100 \mu \mathrm{m}$.

by the density difference between the continuous medium (water) and droplets (oil) ${ }^{[36]}$, The latter outcome may be due to the fact that the emulsion coalescence is at minimal when MCNC-PE is prepared using MCNC1. The results confirmed the aforementioned claims and therefore, the MCNC1 will be focused for further experimentation.

\section{MCNC particle concentration}

The MCNC-PE was subsequently prepared using the $\varphi_{\text {oil }}$ of 0.3 at varies $\mathrm{C}_{\text {menc }}$. The fluorescence microscopy showed the locations of MCNCs (blue fluorescent) around the surface of oil droplets (Figure 4c[iii]). Based on Figure 4a, all MCNC-PE samples displayed monomodal-sized distributions regardless of the $\mathrm{C}_{\text {mcnc. }}$ This is in good agreement with the qualitative data obtained from optical microscopy where the captured emulsion droplets were of uniform spherical size (Figure 4c). The emulsion mean droplet diameter was observed to gradually decrease from
17.34 to $3.58 \mu \mathrm{m}$ upon increment of $\mathrm{C}_{\mathrm{mcnc}}$ from 0.025 to $0.300 \mathrm{wt} \%$ (Figure $4 \mathrm{~b}$ ).

This is mainly attributed to the increased surface coverage by MCNC particles around the emulsion droplets due to the increase in $\mathrm{C}_{\text {mcnc. The }}$ surface coverage $\mathrm{S}_{\text {mcnc }}$ of the emulsion droplets by $\mathrm{MCNC}$ was calculated as follow ${ }^{[24]}$ :

$S_{m c n c}=m_{p} D_{3,2} / 6 h p V_{\text {oil }}$

where $m_{p}$ is the mass of MCNC, $h$ is the MCNC thickness, $\rho$ is the MCNC density, and $V_{\text {oil }}$ is the volume of oil in the emulsion.

The calculated $\mathrm{C}_{\text {monc }}$ of $\mathrm{MCNC}-\mathrm{PE}$ prepared at different are tabulated in Table 1. 


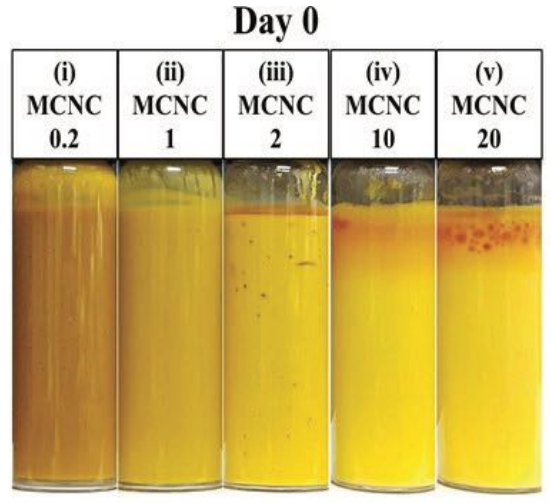

(a)
Day 14

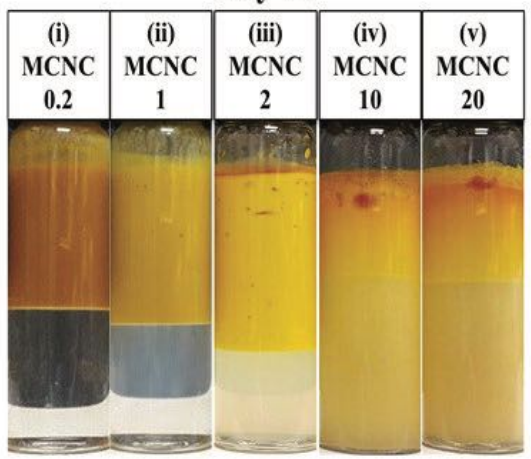

(b)

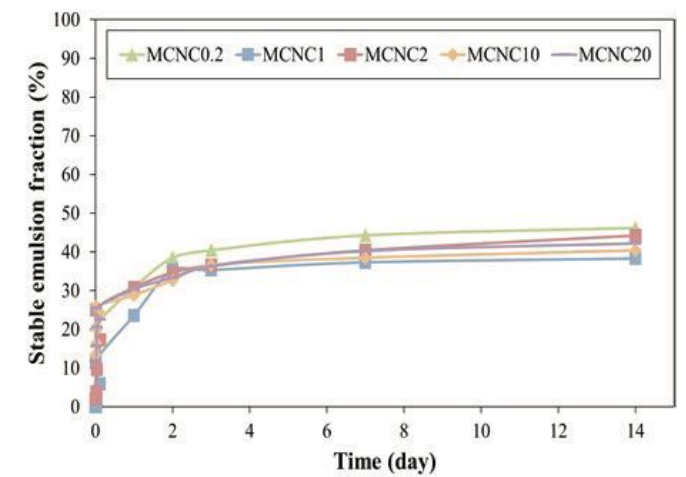

(c)

Figure 3. (a) Day 0 and (b) day 14 of photographs of MCNC-PE with CNC/MNP ratio of (i) 0.2 , (ii) 1, (iii) 2 , (iv) 10 and (v) 20 and (c) creaming indexes.

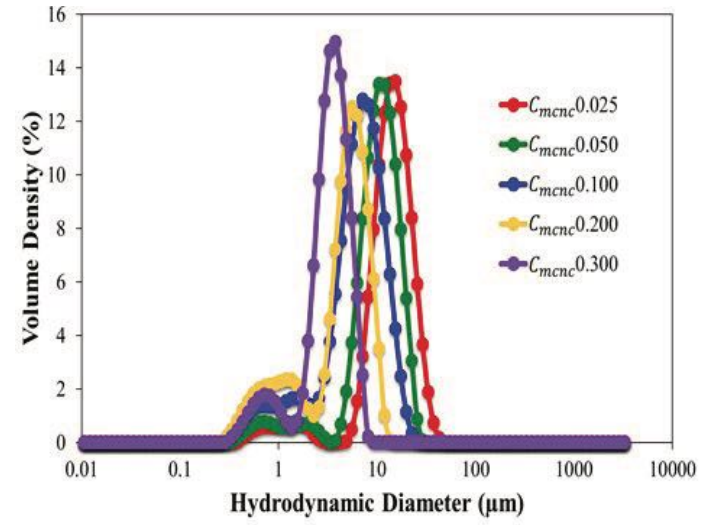

(a)

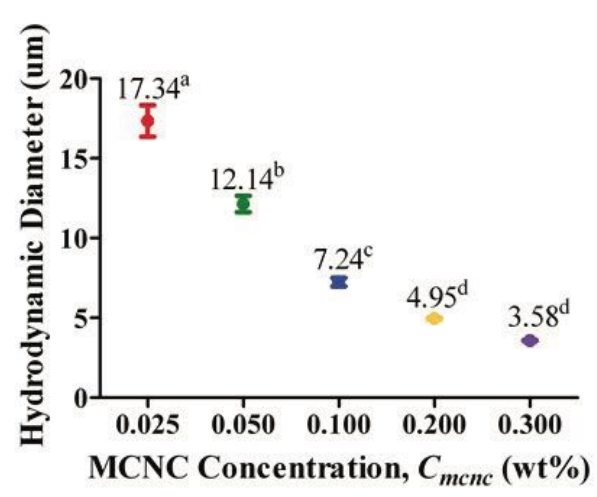

(b)

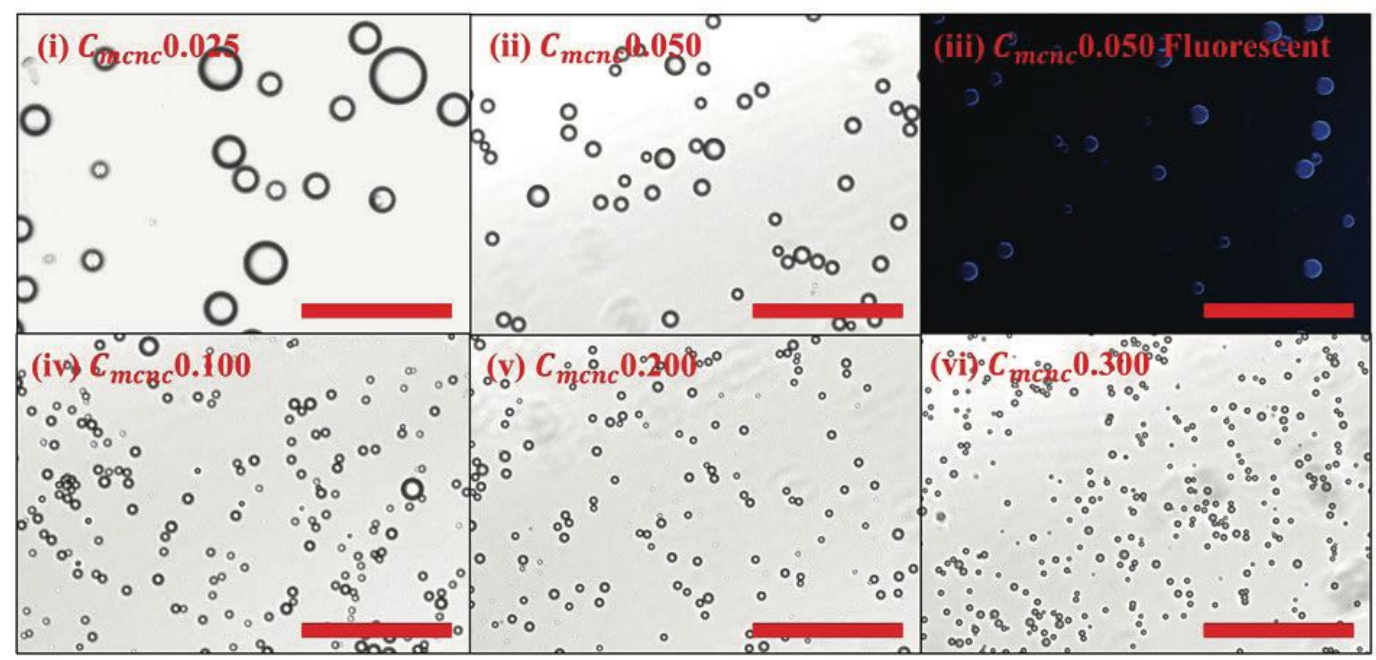

(c)

Figure 4. (a) Droplet size distributions, (b) mean droplet diameters and (c) microscopic images of MCNC-PE as a function of . All formulations contain fixed of 0.3. The standard error of mean of triplicate readings were represented by the error bars in each graph, and different alphabetic letters were significantly different at $\mathrm{P} \leq 0.05$ by Bonferroni's Multiple Comparison Test. All scale bar represents $100 \mu \mathrm{m}$. 
Table 1. Surface coverage, $\mathrm{S}_{\mathrm{mcnc}}$ of $\mathrm{O} / \mathrm{W}$ Pickering emulsion prepared under different $\mathrm{MCNC}$ Concentration, $\mathrm{C}_{\mathrm{mcnc}}$

\begin{tabular}{cc}
\hline $\begin{array}{c}\text { MCNC Concentration, (wt \%) } \\
\mathrm{C}_{\mathrm{mcnc}}\end{array}$ & Surface Coverage, (\%) $\mathrm{S}_{\mathrm{mcnc}}$ \\
\hline 0.025 & 8.496 \\
0.050 & 11.896 \\
0.100 & 15.028 \\
0.200 & 19.410 \\
0.300 & 21.025 \\
\hline
\end{tabular}

As the $\mathrm{C}_{\text {mcnc }}$ grew from 0.025 to $0.300 \mathrm{wt} \%$, the $\mathrm{S}_{\mathrm{mcnc}}$ of the MCNC-PE markedly increased from 8.496 to $21.025 \%$, thereby demonstrating that higher MCNC content leads to higher of the oil globules and thus finer emulsions with enhanced stability against coalescence. The MCNC-PE size changes were then recorded for storage duration of 14 days.

As shown in Figure 5, except for those prepared with $0.025 \mathrm{wt} \%$ of particles, the rest of the MCNC-PEs did not experienced change in the mean droplet diameter throughout the storage at room temperature. At day 1, a slight increase in emulsion diameter (17 to $20 \mu \mathrm{m})$ has been observed in those prepared by $0.025 \mathrm{wt} \% \mathrm{MCNC}$. This is because of the limiting coalescence where the oil globules coalesce to reduce the effective interfacial area between the oil and water phase, which renders a lower energy requirement to remain stable ${ }^{[1-2]}$.

\section{Day 0}

\begin{tabular}{|c||c||c||c||c|}
\hline (i) & (ii) & (iii) & (iv) & (v) \\
$C_{m c n c}$ & $C_{m c n c}$ & $C_{m c n c}$ & $C_{m c n c}$ & $C_{m c n c}$ \\
0.025 & 0.050 & 0.100 & 0.200 & 0.300 \\
\hline & & & & \\
& & & & \\
& & & & \\
& & & \\
& & & \\
\hline
\end{tabular}

(a)

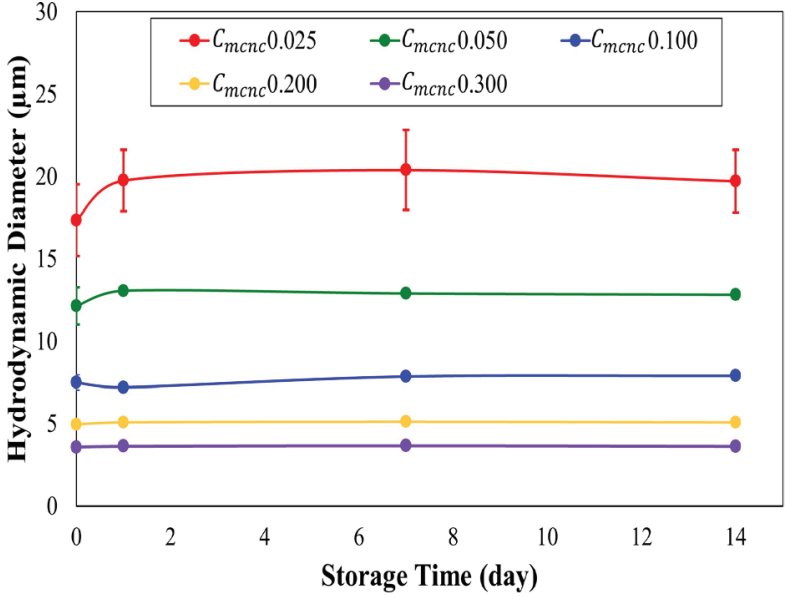

Figure 5. Changes in diameter of MCNC-PE with ranging from 0.025 to 0.300 $\mathrm{wt} \%$ during 14 days of storage.

Figures $6 \mathrm{a}$ and $\mathrm{b}$ show photographs of the MCNC-PE prepared using various $\mathrm{C}_{\mathrm{mcnc}}$ over 14 days storage. Based on Figures $6 \mathrm{~b}$ and $\mathrm{c}$, the CI gradually decreased with increasing $\mathrm{C}_{\text {mcnc }}$. This is not only because of the reduced $\mathrm{MCNC}-\mathrm{PE}$ diameter, but also due to the presence of abundant MCNC particles around the aqueous phase, which results in the formation of particles network that hinder the upward movement of emulsion droplets ${ }^{[36]}$. Overall, it is reasonable to consider that MCNC-PE with smaller droplets diameter (stabilized at higher $\mathrm{C}_{\text {mcnc }}$ ) possess enhanced creaming and coalescence stability as compared to those with the larger ones (stabilized by lower $\mathrm{C}_{\text {menc }}$ ).

\section{Day 14}

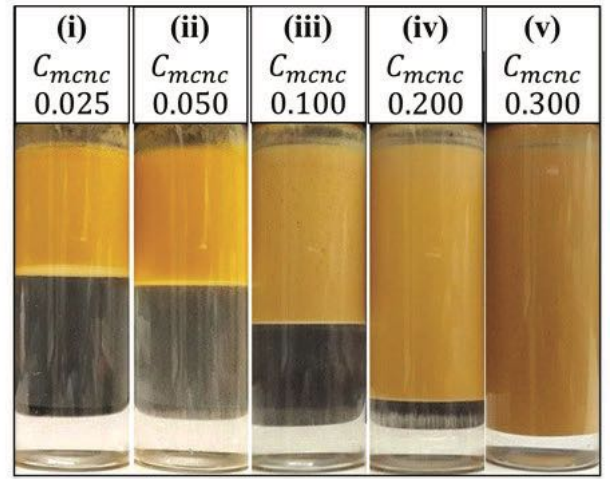

(b)

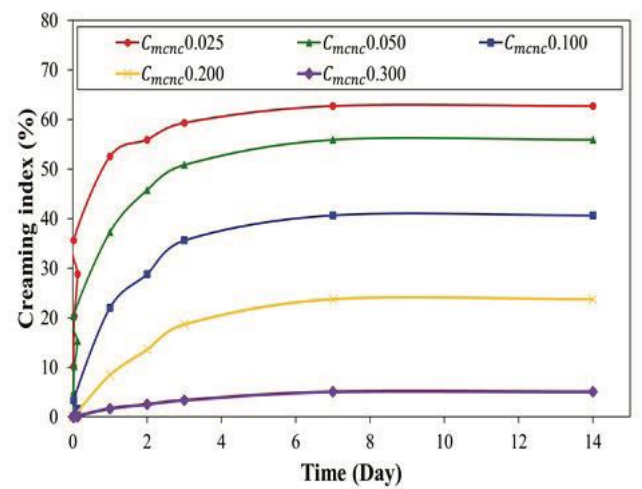

(c) 


\section{Oil volume fraction}

The effect of oil content is another important parameter needing attentions. The size, $\mathrm{S}_{\mathrm{mcnc}}$, coalescence stability and creaming of MCNC-PE were determined as the function of $\varphi_{\text {oil }}$. As shown in Table 2, the of $\mathrm{S}_{\mathrm{mcnc}}$ emulsion initially decreased from 16.556 to $12.070 \%$ when the $\varphi_{\text {oi }}$ increased from 0.1 to 0.2 . The amount of MCNC covering the MCNC-PE then increased from 12.070 to $19.872 \%$ upon further increment of the $\varphi_{\text {oil }}$ to 0.5 . To examine the relationship between the $\varphi_{\text {oil }}$ and $\mathrm{S}_{\mathrm{mcnc}}$ we express the Equation 2 in term of $\mathrm{D}_{3,2} \mathrm{~N}_{\text {oil }}$ " representing Equation 3 (Equation 3) and the derived terms were calculated as shown in Table 2. As expected, the calculated values showed a similar trend to that of $\mathrm{S}_{\text {mcnc }}$, suggesting the increasing $\varphi_{\text {oil }}$ to have a significant impact on the surface properties and droplet sizes for a constant quantity of the particle stabilizer.

$S_{m c n c}=f\left(D_{3,2} / 6 h p V_{o i l}\right)$

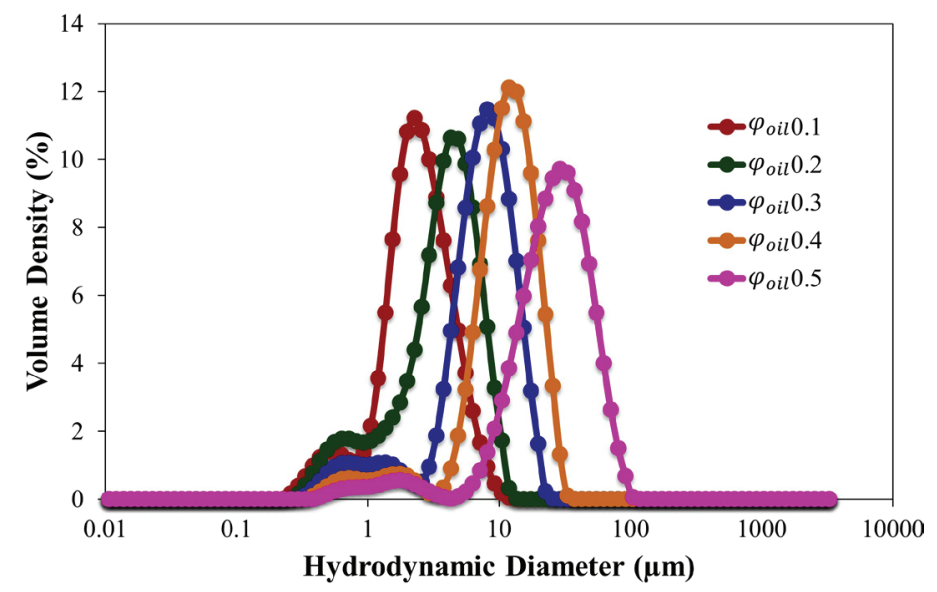

Table 2. Surface coverage, $\mathrm{S}_{\mathrm{mcnc}}$ and calculated values of $\mathrm{D}_{3,2} \mathrm{~V}_{\mathrm{oil}}$ of MCNCPE prepared at different oil volume fraction, $\varphi_{\text {oil }}$.

\begin{tabular}{ccc}
\hline $\begin{array}{c}\text { Oil volume fraction, } \\
\varphi_{\text {oil }}\end{array}$ & $\begin{array}{c}\text { Surface Coverage, } \\
\mathrm{S}_{\mathrm{mcnc}}(\%)\end{array}$ & $\begin{array}{c}(\mu \mathrm{m} / \mathrm{ml}) \\
\mathrm{D}_{3,2} \mathrm{~N}_{\text {oil }}\end{array}$ \\
\hline 0.1 & 16.556 & 0.704 \\
0.2 & 12.070 & 0.513 \\
0.3 & 13.088 & 0.557 \\
0.4 & 15.698 & 0.668 \\
0.5 & 19.872 & 0.845 \\
\hline
\end{tabular}

Based on Figure 7b, the MCNC-PE diameter progressively increases with increasing $\varphi_{\text {oil }}$ (Figure $7 \mathrm{~b}$ ). This is due to the limiting quantity of MCNC particles available for Pickering stabilization at increasing $\varphi_{\text {oil }}$. In this study, the minimum MCNC-PE size of $2.82 \mu \mathrm{m}$ with a narrow monomodal distribution was attained at $\varphi_{\text {oil }}=$ 0.1. Optical microscopy images of MCNC-PEs showed spherical shaped droplets that are uniformly dispersed in the continuous phase regardless of the $\varphi_{\text {oil }}$, with the oil (Figure 7), which is consistent with particle size measurements (Figure 7a).
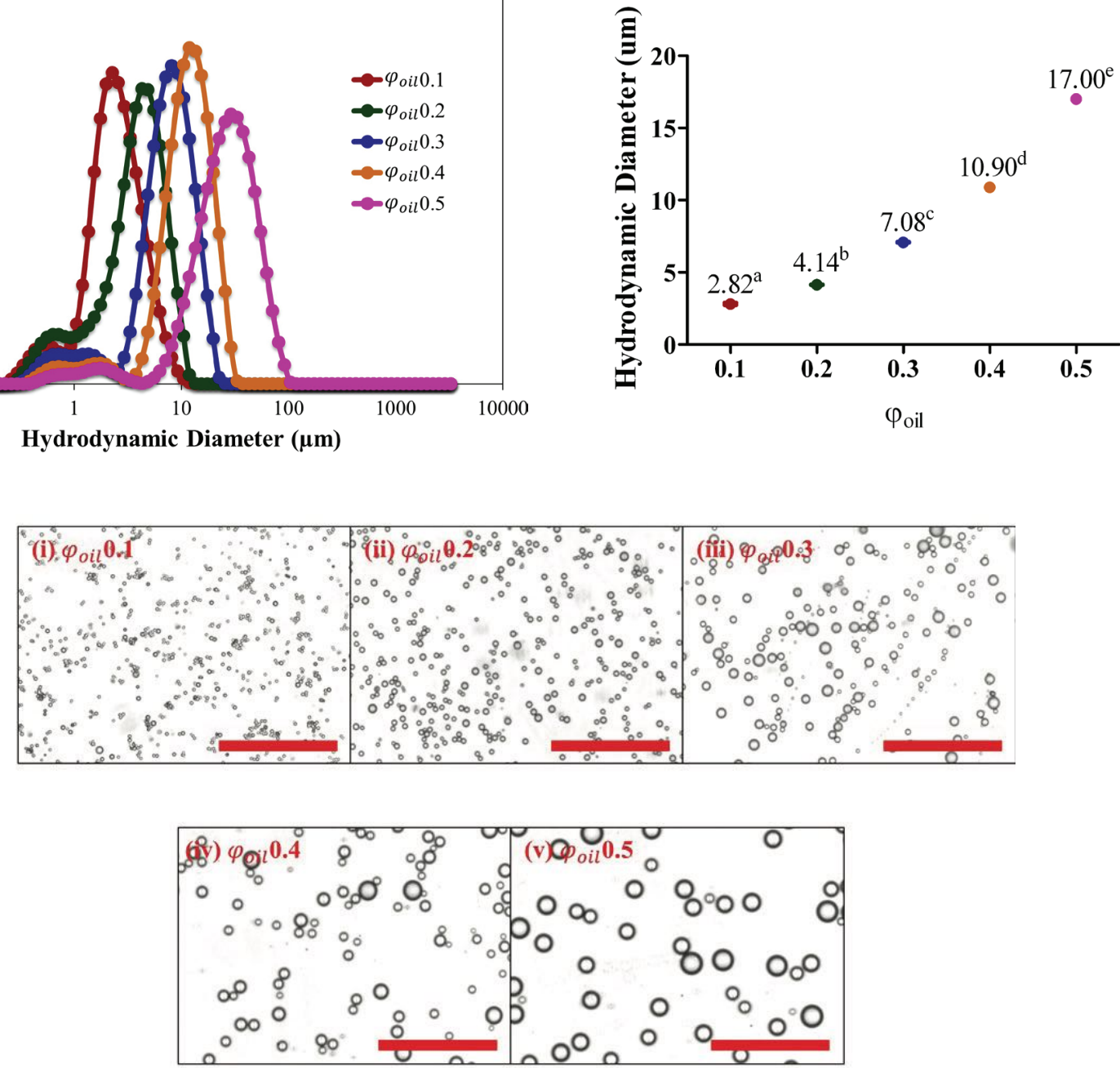

(c)

\footnotetext{
Figure 7. (a) Droplet size distributions, (b) mean droplet diameters, and (c) optical micrographs of MCNC-PE as a function of $\varphi_{\text {oil }}$. All MCNC-PEs were prepared with fixed $\mathrm{C}_{\mathrm{mcnc}}$ of $0.1 \mathrm{wt} \%$. The standard error of the mean of triplicate measurements was represented by the error bars in each graph, and different alphabetic letters were significantly different at $\mathrm{P} \leq 0.05$ using Bonferroni's multiple comparison test. All scale bars represents $100 \mu \mathrm{m}$.
} 
Figure $8 \mathrm{a}$ depicts the change in the size of MCNC-PE upon storage. Note that all the emulsions prepared at varying $\varphi_{\text {oil }}$ from 0.2 to 0.5 showed no significant change in droplet diameter after 14 days of storage. However, a mild increment in droplet size observed at $\varphi_{\text {oil }}=0.1$ and that was most likely due the particles bridging effects as a result of an excessive content of MCNC particles. In this regard,

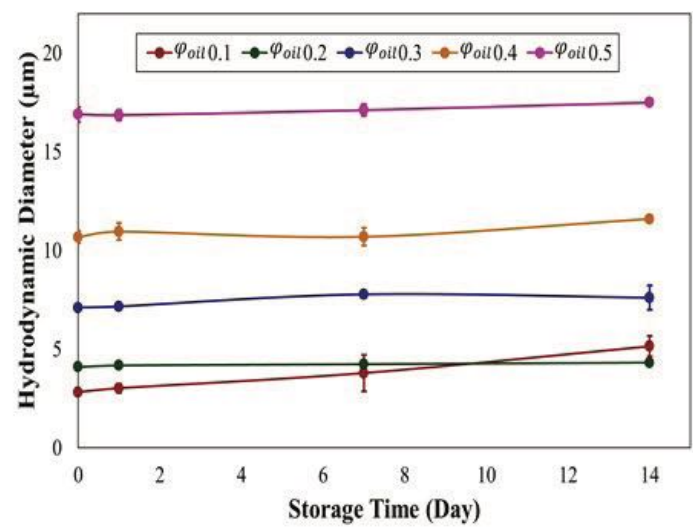

(a) fluorescence microscopy has been performed to visualize the size and morphology of MCNC-PE prepared at $\varphi_{\text {oil }}$ of 0.1. As shown in Figure 8b, the emulsion droplets were terribly agglomerated, promoting the formation of a highly entangled network of MCNC particles in the continuous phase, which rendered larger emulsion sizes.

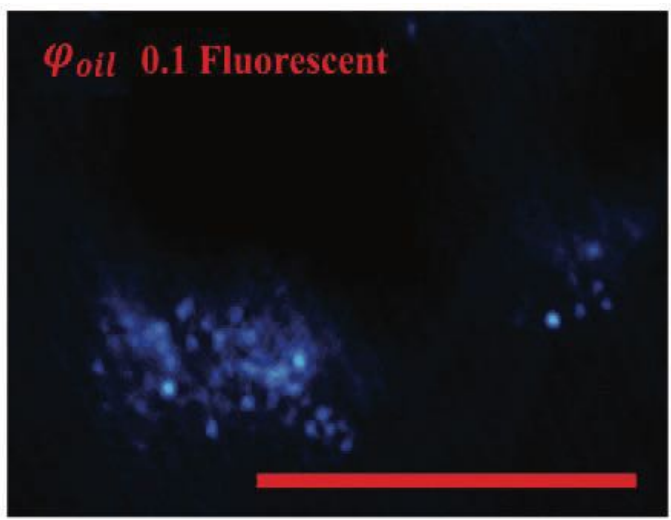

(b)

Figure 8. (a) Changes of MCNC-PE diameter at different, throughout 14 days of storage. (b) Fluorescent microscopic image of MCNC-PE prepared at $=0.1 \varphi_{\text {oil }}$ (40x magnification). All formulations contained a fixed $\mathrm{C}_{\mathrm{mcnc}}$ of $0.1 \mathrm{wt} \%$. The scale bar represents $50 \mu \mathrm{m}$.

Figures $9 \mathrm{a}$ and $\mathrm{b}$ show the photographs of MCNCPE produced with various poil at day 0 and day 14, respectively. The CI decreased as the was increased from 0.1 to 0.5 . It is apparent that a $\varphi_{\text {oil }}$ Pickering emulsion prepared at of 0.5 displayed the lowest degree of creaming among $\varphi_{\text {oil }}$ the emulsion samples. This is because the emulsion CI is directly related to the initial poil during

\section{Day 0}

\begin{tabular}{|c||c||c||c||c|}
\hline (i) & (ii) & (iii) & (iv) & (v) \\
$\varphi_{\text {oil }} 0.1$ & $\varphi_{\text {oil }} 0.2$ & $\varphi_{\text {oil }} 0.3$ & $\varphi_{\text {oil }} 0.4$ & $\varphi_{\text {oil }} 0.5$ \\
\hline- & - & - & - & - \\
& & & & \\
& & & \\
& & & \\
& & & \\
& & & \\
\end{tabular}

(a) emulsion preparation. Since creaming occurred in all samples, and emulsion sample with $=0.1$ holds the lowest oil loading, despite its relatively small $\varphi_{\text {oil }}$ oil droplets diameter, the CI eventually reached a point that corresponded to its . A similar trend was reported by He et al. ${ }^{[10]}$ who studied $\varphi_{\text {oil }}$ the stability of emulsion systems stabilized by graphene oxide.

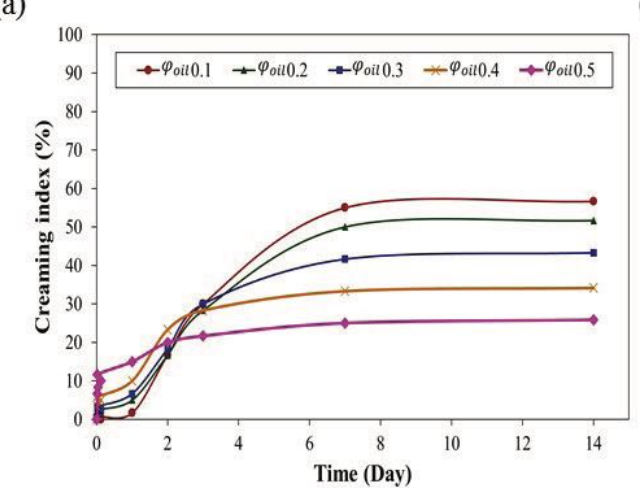

Day 14

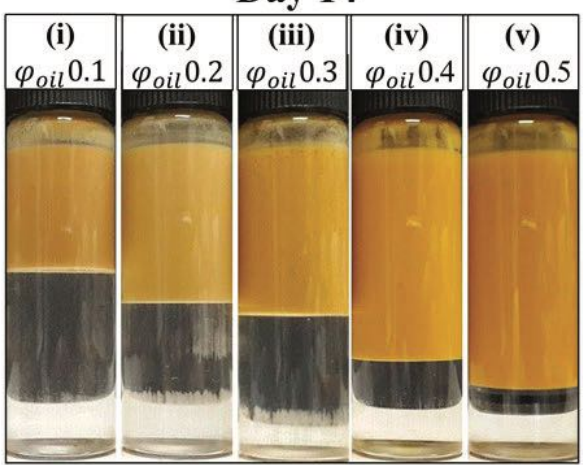

(b)

(c)

Figure 9. Photographs of MCNC-PE at (a) day 0, and (b) day 14. (c) Creaming profile of the Pickering emulsions prepared using different $\varphi_{\mathrm{oil}}$, All formulations contain fixed

$$
\mathrm{C}_{\mathrm{menc}}=0.100 \mathrm{wt} \% \text {. }
$$




\section{Effect of ionic strength on the MCNC-PE prop- erties}

One of the normally encountered stresses in the human body is the ionic content. Here, the influence of ionic strength was evaluated by varying the $\mathrm{NaCl}$ concentration from 0 to $500 \mathrm{mM}$. All MCNC-PE samples were stored at room temperature for 14 days prior to analysis. Figures $10 \mathrm{a}-\mathrm{c}$ revealed that all MCNC-PEs show similar mean droplet diameter around 7 to $8 \mu \mathrm{m}$ with a narrow size distribution regardless of the salt concentrations (Figure 10a). Conversely, minor increment in emulsion creaming $(<10 \%$ of $\mathrm{CI})$ was observed with increasing ionic content (Figure 10b).
It should be noticed that the obtained optical microscopic images displayed the aggregated bound droplets at all $\mathrm{NaCl}$ concentrations (Figure 10c). The observed agglomeration could be owing to the electrostatic screening effects by an increase in the ionic strength of the continuous phase ${ }^{[28]}$. Noteworthy, the outcomes, as supplemented by mastersizer analysis demonstrated that the MCNC-PEs were highly stable against coalescence for 2 weeks despite a pronounced aggregation upon the addition of $\mathrm{NaCl}$. A possible explanation for this scenario is that under conditions of high particle charge and weak screening, the coalescence of the vast majority of particles is severely impeded by the presence of a fixed quantity of MCNC particles.

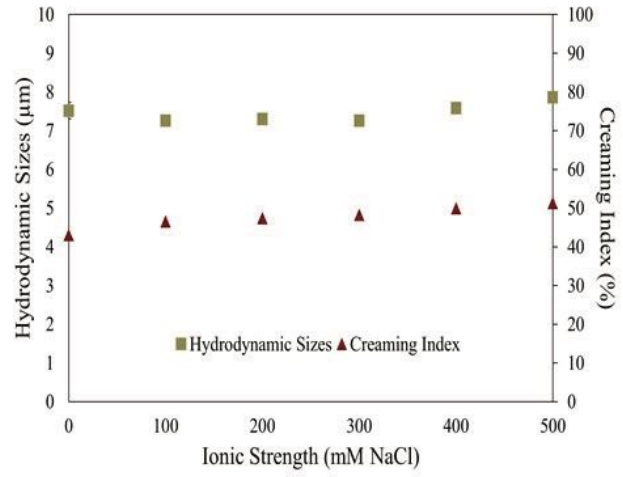

(a)

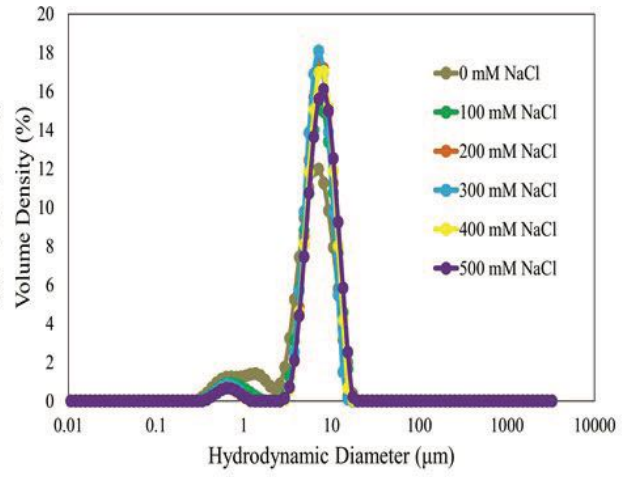

(b)

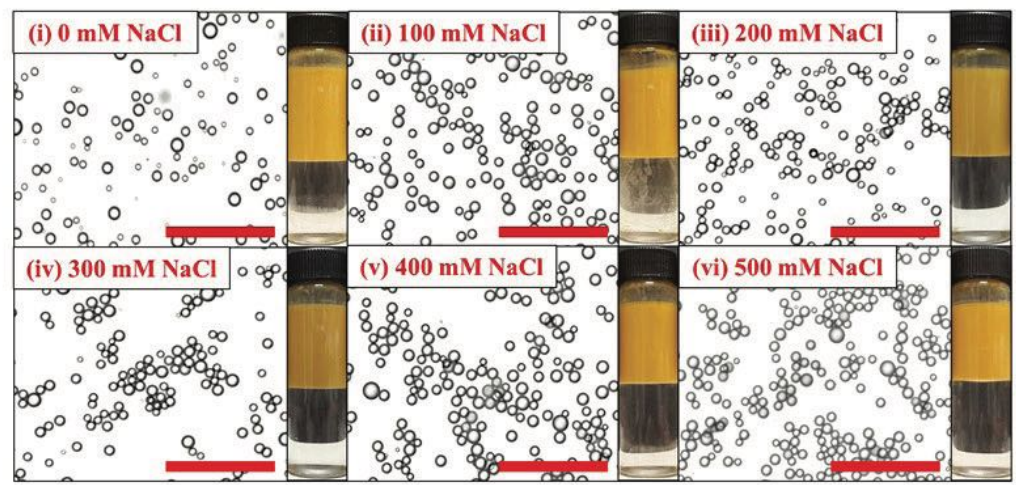

(c)

Figure 10. (a) Mean droplet diameter and creaming profiles, (b) Droplet size distribution and (c) optical micrographs of MCNC-PE as a function of ionic strength. All formulations contain fixed $\varphi_{\text {oil }}$ of 0.3 and $\mathrm{C}_{\mathrm{mcnc}}$ of $0.100 \mathrm{wt} \%$. The samples were stored at room temperature for 14 days prior to measurement. All scale bar represents $100 \mu \mathrm{m}$.

To verify this further, we prepared two MCNC dispersions containing $0.1 \mathrm{wt} \% \mathrm{MCNC}$ particles. The addition of $500 \mathrm{mM} \mathrm{NaCl}$ into the dispersion triggered the partial sedimentation of the MCNC particles (Figure 11).

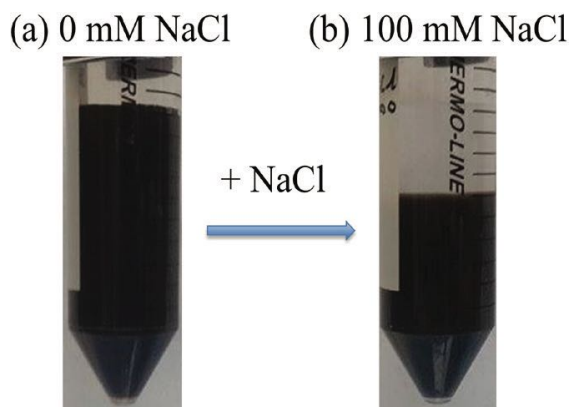

Figure 11. MCNC suspensions (a) without $\mathrm{NaCl}$ and (b) with $500 \mathrm{mM} \mathrm{NaCl}$.
The latter confirmed the hypothesis that described the correlation between charge effects and emulsion aggregation. The results of current study suggest that the stability of MCNC-stabilized Pickering emulsions against creaming and coalescence was unaffected by ionic strength $(\mathrm{NaCl})$ from 100 to $500 \mathrm{mM}$. In comparison to other existing Pickering emulsions in the literature where none of them remained physically unchanged (in size and surface coverage) when subjected to ionic strength variations, our results have shown significant advances on the stability of the green MCNC-PE against the environmental ionic strength ${ }^{[37-40]}$.

\section{Conclusion}

The present study investigated the effects of $\mathrm{CNC} / \mathrm{MNP}$ ratios, $\mathrm{C}_{\mathrm{mcnc}}$ and ionic strength on the emulsion stability and ooil physical properties of MCNC-PE. At fixed $\varphi_{\text {oil }}$ 
of 0.3 , extremely stable emulsions with minimum droplet sizes of about $7 \mu \mathrm{m}$ could be prepared using $0.1 \mathrm{wt} \%$ $\mathrm{C}_{\text {menc }}$ with $\mathrm{CNC} / \mathrm{MNP}$ ratio of $\leq 1$. It was found that the emulsion droplet sizes decreased gradually with improved creaming stability with the increase in $\mathrm{S}_{\mathrm{mcnc}}$. This could be mainly attributed to the increased droplet Smcnc when the $\mathrm{C}_{\text {mcnc }}$ was increased from 0.025 to $0.300 \mathrm{wt} \%$. An increase in the $\varphi_{\text {oil }}$ led to formation of larger emulsion droplet sizes. Our study showed that MCNC-PE were stable against droplet coalescence with the $\mathrm{S}_{\mathrm{mcnc}}>11 \%$. No instability in term of emulsion droplet size and phase separation were observed upon changes in ionic strength from 0 to $500 \mathrm{mM}$. These findings are useful in the development of Pickering emulsion-based delivery system with predictable emulsion stability and droplet size variation.

\section{Conflict of Interest}

The authors declare that there is no conflict of interest.

\section{Acknowledgements}

Authors thank the Ministry of Higher Education Malaysia who funded this study through Fundamental Research Grant Scheme (FRGS/1/2017/STG07/MUSM/03/1). The authors also gratefully acknowledge the support from Graduate Merit Research Scholarship and Advanced Engineering Platform (AEP), Monash University Malaysia.

\section{Reference}

1. Caenn R, Darley H, Gray G. Composition and properties of drilling and completion fluids. Gulf Professional Pub Waltham, MA 2011: 537-596.

2. Kokal S, and Wingrove M. Emulsion separation index: From laboratory to field case studies. SPE annual technical conference and exhibition. SPE Journal, Dallas 2000

3. Tadros TF. Emulsion formation, stability, and rheology in: Tadros TF (editors). Emulsion formation and stability. Weinheim, Germany: WileyVCH Verlag GmbH \& Co. KGaA; 2013. p. 1-8.

4. Tang J, Quinlan PJ, Tam KC. Stimuli-responsive Pickering emulsions: Recent advances and potential applications. Soft Matter 2015; 11(18): 3512-3529.

5. Wahlgren M, Engblom J, Sjöö M, et al. The use of micro- and nanoparticles in the stabilisation of Pickering- type emulsions for topical delivery. Curr Pharm Biotechnol 2013; 14: 1222-1234

6. Berton-Carabin CC, and Schroen K. Pickering emulsion for food applications: Background, trends, and challenges. Annu Rev Food Sci Technol 2015; 6: 263-297

7. Rousseau D. Fat crystals and emulsion stability - a review. Food Res. Int. 2000; 33: 3-14.

8. Rayner M, Marku D, Eriksson M, et al. Biomass-based particles for the formulation of Pickering type emulsions in food and topical applications. Colloids Surf A Physicochem Eng Asp 2014; 458: 48-62.

9. Aveyard R, Binks BP, Clint JH. Emulsions stabilised solely by colloidal particles. Adv Colloid Interface Sci 2003; 100-102: 503-546.

10. He Y, Wu F, Sun X, et al. Factors that affect Pickering emulsions stabilized by graphene oxide. ACS Appl Mater Interfaces 2013; 5(11): 4843-4855.

11. Ramsden W. Separation of solids in the surface-layers of solutions and 'suspensions' (observations on surface-membranes, bubbles, emulsions, and mechanical coagulation) - preliminary account. Proc R Soc Lond
1903; 72: 156-164

12. Pickering SU. Emulsions. J Chem Soc 1907; 91: 2001-2021.

13. Frelichowska J, Bolzinger M-A, Pelletier J, et al. Topical delivery of lipophilic drugs from O/W Pickering emulsions. Int J Pharm 2009; 371(1-2): 56-63.

14. Binks BP. Particles as surfactants-similarities and differences. Curr Opin Colloid Interface Sci 2002; 7(1-2): 21-41.

15. Timgren A, Rayner M, Sjöö M, et al. Starch particles for food based Pickering emulsions. Procedia Food Sci 2011; 1: 95-103.

16. Jia X, Xu R, Shen W, et al. Stabilizing oil-in-water emulsion with amorphous cellulose. Food Hydrocoll 2015; 43: 275-282.

17. Song X, Pei Y, Qiao M, et al. Preparation and characterizations of Pickering emulsions stabilized by hydrophobic starch particles. Food Hydrocoll 2015; 45: 256-263.

18. Chevalier Y, and Bolzinger M. Emulsions stabilized with solid nanoparticles: Pickering emulsions. Colloids Surf A Physicochem Eng Asp 2013; 439: 23-34.

19. Wu J, Ma GH, Recent studies of Pickering emulsions: Particles make the difference. Small 2016; 12(34): 4633-4648.

20. Frelichowska J, Bolzinger M-A, Valour J-P, et al. Pickering W/O emulsions: Drug release and topical delivery. Int J Pharm 2009; 368(1-2): 7-15.

21. Marku D, Wahlgren M, Rayner M, et al. Characterization of starch Pickering emulsions for potential applications in topical formulations. Int J Pharm 2012; 428(1-2): 1-7.

22. Zoppe JO, Venditti RA, \& Rojas OJ. Pickering emulsions stabilized by cellulose nanocrystals grafted with thermo-responsive polymer brushes. J Colloid Interface Sci 2012; 369(1): 202-209.

23. Capron I \& Cathala B. Surfactant-free high internal phase emulsions stabilized by cellulose nanocrystals. Biomacromolecules 2013 ; 14(2): 291-296.

24. Kalashnikova I, Bizot H, Cathala B, et al. New Pickering emulsions stabilized by bacterial cellulose nanocrystals. Langmuir 2011; 27(12): 7471-7479.

25. Cunha AG, Mougel J, Cathala B, et al. Preparation of double Pickering emulsions stabilized by chemically tailored nanocelluloses. Langmuir 2014; 30(31): 9327-9335.

26. Low LE, Wong SK, Tang SY, et al. Production of highly uniform Pickering emulsions by novel high-intensity ultrasonic tubular reactor (HUTR). Ultrason. Sonochem 2019; 54: 121-128.

27. Wu W, Huang F, Pan S, et al. Thermo-responsive and fluorescent cellulose nanocrystals grafted with polymer brushes. J Mater Chem A 2015; 3(5): 1995-2005.

28. Tang J, Lee MFX, Zhang W, et al. Dual responsive Pickering emulsion stabilized by poly[2-(dimethylamino)ethyl methacrylate] grafted cellulose nanocrystals. Biomacromolecules 2014; 15(8): 3052-3060.

29. Low LE, Tey BT, Ong BH, et al. Palm olein-in-water Pickering emulsion stabilized by $\mathrm{Fe}_{3} \mathrm{O}_{\text {-cellulose nanocrystal nanocomposites }}$ and their responses to $\mathrm{pH}$. Carbohydr Polym 2016; 155: 391-399.

30. Low LE, Tey BT, Ong BH, et al. Unravelling $\mathrm{pH}$-responsive behaviour of $\mathrm{Fe}_{3} \mathrm{O}_{4} @$ CNCs-stabilized Pickering emulsions under the influence of magnetic field. Polymer 2018; 141: 93-101.

31. Low LE, Tan LT-H, Goh B-H, et al. Magnetic cellulose nanocrystal stabilized Pickering emulsions for enhanced bioactive release and human colon cancer therapy. Int J Biol Macromol 2019; 127: 76-84.

32. Low LE, Tey BT, Ong BH, et al. A facile and rapid sonochemical synthesis of monodispersed $\mathrm{Fe}_{3} \mathrm{O}_{4} @$ cellulose nanocrystal nanocomposites without inert gas protection. Asia-pac J Chem Eng 2018; 13(4): e2209.

33. Low LE, Siva SP, Ho YK, et al. Recent advances of characterization techniques for the formation, physical properties and stability of Pickering emulsion. Adv Colloid Interface Sci 2020; 277: 102117.

34. Low LE, Tey BT, Ong BH, et al. Dispersion stability, magnetivity, and wettability of cellulose nanocrystal (CNC)-dispersed superparamagnetic $\mathrm{Fe}_{3} \mathrm{O}_{4}$ nanoparticles: Impact of $\mathrm{CNC}$ concentrationt. RSC Adv 2016; 6(114): 113132-113138.

35. Kalska-Szostko B, Wykowska U, Satula, et al. Thermal treatment of magnetite nanoparticles. Beilstein J Nanotechnol 2015; 6: 13851396.

36. Mwangi WW, Ho KW, Tey BT, et al. Effects of environmental factors on the physical stability of Pickering-emulsions stabilized by chitosan particles. Food Hydrocoll 2016; 60: 543-550.

37. Fouilloux S, Malloggi F, Daillant J, et al. Aging mechanism in model Pickering emulsion $\dagger$. Soft Matter 2016; 12(3): 900-904.

38. Tan Y, Xu K, Niu C, et al. Triglyceride-water emulsions stabilised by starch-based nanoparticles. Food Hydrocoll 2014; 36: 70-75.

39. Destribats M, Ravaine S, Heroguez V, et al. Outstanding stability of poorly-protected Pickering emulsions. Progr Colloid Polym Sci 2010; 137: 13-18.

40. Gautier F, Destribats M, Perrier-Cornet R, et al. Pickering emulsions with stimulable particles: From highly- to weakly-covered interfacest. Phys Chem Chem Phys 2007; 9(48): 6455-6462. 